\title{
'PACIFICANDO' DOUTRINAS CRISTÃS: \\ PROTESTANTISMO/PENTECOSTALISMO E SEU APODERAMENTO POR SOCIEDADES INDÍGENAS
}

\section{'PACIFYING' CHRISTIAN DOCTRINES: PROTESTANTISM/PENTECOSTALISM AND YOUR APPROVAL FOR INDIGENOUS SOCIETIES}

Graziele Acçolini (UFGD/CNPq - grazieleaccolini@ hotmail.com)

\begin{abstract}
RESUMO
NESTE ARTIGO PRETENDO APRESENTAR UMA BREVE DISCUSSÃO ACERCA DO PROTESTANTISMO E MAIS ESPECIFICAMENTE DO PENTECOSTALISMO E SUA CHEGADA AO BRASIL, PAÍS CUJA FORMAÇÃO SE DEU SOB O CRISTIANISMO CATÓLICO, VIDE A ATUAÇÃO DA COMPANHIA DE JESUS E SUAS MISSÕES 'CIVILIZADORAS' AINDA NO SÉCULO XVI. ASSIM PRETENDO DAR ESPECIAL ATENÇÃO À INSERÇÃO DESSAS DOUTRINAS CRISTÃS, O PROTESTANTISMO E PENTECOSTALISMO, ENTRE ALGUMAS SOCIEDADES INDÍGENAS. PARA TANTO, ESBOÇAREI POSICIONAMENTOS TEÓRICOS SOBRE O TEMA, BEM COMO APONTAMENTOS SOBRE O PENTECOSTALISMO PRESENTE NAS TERRAS INDÍGENAS DO OESTE PAULISTA CONSTITUÍDAS PELOS TERENA, AQUI MINHA INSPIRAÇÃO A TAL ARTIGO, E TAMBÉM PELOS GUARANI NHANDEVA, KAINGÁNG E OS KRENÁK DESDE O INÍCIO DO SÉCULO XX., SÃO ELAS: VANUÍRE (MUNICÍPIO DE ARCO-IRIS/SP), ICATÚ (BRAÚNA/SP) E ARARIBÁ (AVAÍ/SP). PARTICULARMENTE, ME ATEREI A VANUÍRE, POIS SE TRATA DA ÁREA A QUE TIVE MAIOR ACESSO ESPECIALMENTE DURANTE 2009 E 2010.
\end{abstract}

PALAVRAS CHAVE: PROTESTANTISMO/PENTECOSTALISMO, TERENA, T.I. VANUÍRE/OESTE PAULISTA.

\section{ABSTRACT}

IN THIS ARTICLE IT INTENDS TO COME AN ABBREVIATION DISCUSSION CONCERNING THE PROTESTANTISM AND MORE SPECIFICALLY OF THE PENTECOSTALISM AND YOUR ARRIVAL TO BRAZIL, COUNTRY WHOSE FORMATION FELT UNDER THE CATHOLIC CHRISTIANITY, VIDE THE PERFORMANCE OF JESUS COMPANY AND YOUR MISSIONS 'CIVILIZING' STILL IN THE CENTURY XVI. LIKE THIS, IT INTENDS TO FEEL SPECIAL ATTENTION TO THE INSERT OF THOSE CHRISTIAN DOCTRINES, THE PROTESTANTISM AND THE PENTECOSTALISM, AMONG SOME INDIGENOUS SOCIETIES. FOR SO MUCH, THEORETICAL PLACEMENTS WILL BE SKETCHED ON THE THEME, AS WELL AS NOTES ON THE PRESENT PENTECOSTALISM IN THE INDIGENOUS LANDS OF THE WEST FROM SÃO PAULO CONSTITUTED BY TERENA, HERE THE INSPIRATION FOR SUCH ARTICLE, AND ALSO FOR THE GUARANI NHANDEVA, KAINGÁNG AND KRENÁK SINCE THE BEGINNING OF THE CENTURY XX, THEY ARE THEM: VANUÍRE (MUNICIPAL DISTRICT OF ARCH-IRIS/SP), ICATÚ (BRAÚNA/SP) AND ARARIBÁ (AVAÍ/SP). PARTICULARLY, IT WILL BE OUTSTANDING VANUÍRE, BECAUSE IT IS TREATED OF THE AREA WHICH THERE WAS LARGER ACCESS, ESPECIALLY DURING 2009 AND 2010.

WORDS KEY: PROTESTANTISM/PENTECOSTALISM, TERENA, T.I. VANUÍRE/OESTE FROM SÃO PAULO. 
Neste artigo pretendo apresentar uma breve discussão acerca do protestantismo e mais especificamente do pentecostalismo e sua chegada ao Brasil, país cuja formação se deu sob o cristianismo católico, vide a atuação da Companhia de Jesus e suas missões 'civilizadoras' ainda no século XVI. Assim pretendo dar especial atenção à inserção dessas doutrinas cristãs, o protestantismo e o pentecostalismo, entre algumas sociedades indígenas.

Para tanto, esboçarei posicionamentos teóricos sobre o tema, bem como apontamentos sobre o pentecostalismo presente nas Terras Indígenas do oeste paulista constituídas pelos Terena e também pelos Guarani Nhandeva, Kaingáng e os Krenák desde o início do século XX., são elas: Vanuíre (município de Arco-Iris/SP), Icatú (Braúna/SP) e Araribá (Avaí/SP). Particularmente, me aterei a Vanuíre, pois se trata da área a que tive maior acesso especialmente durante 2009 e 2010.

E a partir deste viés, os povos indígenas em relação à apropriação do cristianismo e especialmente da doutrina protestante e pentecostal frente às suas próprias formas de religiosidade, que pretendo desenvolver esse artigo. Nesse sentido, desejo apresentar o protestantismo e o pentecostalismo de forma geral e entre os povos indígenas, especialmente nas Terras Indígenas do oeste paulista, a fim de apontar algumas maneiras de abordar o tema.

Essa escolha se deu, pois trabalhei com o tema durante meu mestrado e doutorado entre os Terena do Pantanal de Mato Grosso do Sul, trilhando as elaborações de antropólogos que se debruçaram sobre manifestações religiosas entre os povos indígenas e que também abordaram o tema da apropriação do protestantismo e do pentecostalismo por essas sociedades.

Pesquisei uma igreja protestante entre os Terena da aldeia Bananal, Posto Indígena/T.I. Taunay/Ipegue, pertencente ao município de Aquidauana; a Uniedas, que está entre eles desde a chegada dos missionários anglo-norte-americanos em 1913 e que possui desde a década de 1970 toda sua organização formada somente por Terena, inclusive os pastores e mais, com os cultos realizados na língua terena. Conheci esse cenário em 1994 que também inclui igrejas pentecostais e neo-pentecostais (ACÇOLINI, 2004).

Esse trabalho culminou em minha tese que intitulei Protestantismo à moda Terena, cuja hipótese central foi o processo de terenização do protestantismo e do pentecostalismo em linhas gerais. Junto a esse processo, observei não somente a manutenção, mas a reestruturação do xamanismo, sob novas roupagens como contraponto para ancorar essa hipótese, tendo em 


\section{Nanduty}

vista a recorrência dos adeptos protestantes e pentecostais a esse sistema religioso e a reconstrução dinâmica de identidades (como o encontro com um xamã pentecostal).

Nesse sentido, pretendo em paralelo a essa pesquisa, e tendo particular atenção aos Terena, tecer breves comentários acerca das religiões presentes na T.I. Vanuíre do oeste paulista e as etnias ali presentes.

\section{PROTESTANTISMO E PENTECOSTALISMO NO BRASIL E OS POVOS INDÍGENAS}

O protestantismo e o pentecostalismo no Brasil é fruto de um longo processo de inserção do chamado protestantismo de missão, o protestantismo proselitista inglês e principalmente norte-americano que no século XIX já percorria o Brasil e se disseminou mesmo a partir do século XX no contexto republicano, especialmente com a laicização empreendida pelo novo Estado.

Seu objetivo principal ainda é hoje o de desenvolver o proselitismo e expandir o evangelho até a última sociedade de todos os continentes (só como observação: não é a toa que podemos encontrar missionários coreanos no meio do Pantanal sul-mato-grossense). Quer dizer, em sua origem já se colocam no cenário mundial. Essas missões são caudatárias da teologia dos avivamentos, movimento de renovação do protestantismo clássico norteamericano do século XIX.

O metodismo, por exemplo, com sua ênfase na conversão e não no batismo fortalecia a confiança na capacidade do indivíduo de sempre estar em busca da perfeição; subjacente ao princípio do voluntariado encontramos os ideais liberais reforçando a visão do homem como senhor de sua vontade e responsável por suas ações. As ideias iluministas que em um primeiro momento enfraqueceram o credo protestante foram incorporadas tendo como pano de fundo o idealismo romântico do homem comum e da democracia popular (MENDONÇA, 1982: $77,78)$.

Aliado aos fatores filosóficos e sua concepção do valor do homem, a empresa missionária carregava consigo a doutrina arminiana do infinito amor de Deus para com todos os homens, tarefa que só podia se realizar com a extensão das missões a todos os cantos do mundo.

Nesse intento, Mendonça (1982), um dos pesquisadores que se debruçou sobre o tema, expõe que entre o final do século XVIII e início do XIX já se encontravam nos EUA mais de 
vinte associações preocupadas em evangelizar os povos indígenas e dar assistência religiosa às frentes pioneiras.

Apesar das denominações terem organizado durante o século XIX suas próprias associações missionárias, foi mantida certa unidade teológica como forma de combate à Igreja católica; era necessário nesse período uma coligação que ideologicamente unisse esforços contra o credo católico. Isso foi alcançado a partir de uma simplificação teológica e litúrgica formando assim uma unidade básica. Mesmo os mais ferrenhos calvinistas, como os Presbiterianos e Batistas abriram mão da doutrina da predestinação em nome do voluntarismo, valorizando o homem em seu empenho em busca do 'progresso', com o intuito de manter novos convertidos.

Assim, junto com o caráter de difusor ideológico de uma visão de mundo que diferia marcantemente, por exemplo, da nossa em relação à crença e à sociedade de origem, instrumentalmente a educação favoreceu, pelo menos em alguns lugares e com determinados grupos, a entrada e permanência dos missionários, pois além de divulgar e transmitir os princípios da nova crença e ter como meta angariar novos conversos, também oferecia a educação formal, alfabetizadora, em locais que o ensino oficial não conseguia alcançar.

É interessante pontuar a questão do livre acesso à Bíblia inclusive pelos leigos, pois acredito que esse traço favorece a ênfase dada por cada igreja a determinados pontos doutrinários e passagens bíblicas, que os ilustram e que emblematizam comportamentos. É a partir desse aspecto que acredito que este fenômeno religioso se abre e demonstra apresentar uma grande versatilidade frente a grupos de pessoas e contextos socioculturais específicos.

Mais um elemento que desembocou na empresa missionária foi a concepção milenarista da história; a ideia da segunda vinda de Cristo à terra. Enquanto um evento cósmico inclui todas as nações do mundo que, invocadas e preparadas pela civilização cristã mais avançada, a norte-americana que, pautada no tripé religião, moralidade e educação, deveria levar o conhecimento do evangelho e sua mensagem até os últimos cantos do planeta com o intuito de apressar esse retorno.

O início e o desenvolvimento do protestantismo e do pentecostalismo especialmente no Brasil se deu, como mencionei, no contexto republicano. Paul Freston (1994), por exemplo, dentre uma gama importante de pesquisadores, propõe que este pode ser compreendido como a história de 3 ondas de implantação de igrejas. A primeira onda, denominada de pentecostalismo clássico, se dá no momento de origem e expansão do pentecostalismo para 
'todos os continentes'. Corresponde à década de 1910 com a chegada da Congregação Cristã no Brasil (1910) e da Assembleia de Deus (1911); essas duas igrejas predominam no Brasil durante 40 anos.

A segunda onda, denominada de pentecostalismo neoclássico, ocorre no ano de 1950 e se estende até 1960, com o período de urbanização e formação de uma sociedade de massas, o que possibilitou um crescimento do pentecostalismo que rompeu com os modelos existentes; é um momento em que o campo pentecostal experimenta uma fragmentação: as relações com a sociedade nacional passam por um acentuado dinamismo e surgem três grandes igrejas, a Igreja do Evangelho Quadrangular (1953), a Igreja Evangélica ‘O Brasil para Cristo' (1955) e a Igreja Pentecostal Deus é Amor (1962). Essas duas ondas receberam influências diretas do pentecostalismo norte-americano.

A terceira onda, denominada de neopentecostal, se inicia no final dos anos de 1970 e ganha força na década de 1980 após a modernização autoritária no país, principalmente na área das comunicações quando a urbanização atinge grande parte da população e o 'milagre econômico' brasileiro da década de 1970 está exaurido; como grandes representantes temos a Igreja Universal do Reino de Deus (1977) e a Igreja Internacional da Graça de Deus (1980).

Essa classificação histórica de Freston (1994) não é unívoca no cenário de estudos sobre pentecostalismo; Bittencourt Filho (1989: 27), por exemplo, acredita que as igrejas que se seguiram às do pentecostalismo clássico devem ser denominadas de "pentecostalismo autônomo", pois para ele estas nasceram independentes tanto do protestantismo clássico quanto do pentecostalismo clássico.

Com outra proposta, Mendonça (1990) acredita que as pentecostais devam ser classificadas como "clássicas" e igrejas de "cura divina" por se constituírem em pequenos grupos, cujos empreendimentos são locais e a liderança individual, sem estabilidade e doutrinas definidas. Inclusive, Mendonça (1990) faz uma colocação sobre as "ondas" de Freston (1994), aliás, sarcástica, dizendo que, grosso modo, ondas 'vão e vem'.

No entanto, não parece ser esse o sentido empregado por Freston (1994) e nem por quem o corroborou como Ricardo Mariano (1999) que, de certa forma, complementa as afirmações de Freston (1994), argumentando que no que se refere à questão teológica, a primeira e segunda ondas não apresentam grandes diferenças, apenas se especificam no que tange a ênfase que cada qual dá a um ou outro dom do Espírito Santo: a primeira enfatizando a glossolalia, enquanto a segunda o dom da cura. Conclui, colocando que o recorte entre as 
duas ondas pode se dar pelo critério do corte histórico-institucional, mas não por diferenças teológicas.

Aqui no Brasil, o protestantismo e o pentecostalismo passaram por várias modificações para que pudesse se consolidar efetivamente em igrejas, salvaguardando o número de convertidos.

Como exemplo, podemos apontar que, apesar da ideologia incorporada ao pensamento institucional no Brasil ter sido o do pré-milenarismo (em cuja concepção, há um afastamento das questões sociais, recaindo as preocupações sobre a evangelização de todos os povos, pois o reino virá por ação divina independente da atuação do homem), isso não quer dizer que tenha repercutido ou sido transplantado simplesmente seu caráter conservador nos lugares onde conseguiu abertura para se consolidar, pois em cada comunidade onde a crença se inseriu, foi interpretado a partir dos elementos culturais e do contexto histórico então em jogo, pois se transformando em elemento endógeno, puderam ser encarados como algo em oposição justamente ao estabelecido e legitimado, que no caso do Brasil, era o catolicismo, mesmo em sua versão popular.

Também é interessante apontar que com a inserção do protestantismo e do pentecostalismo na sociedade brasileira, houve uma ruptura efetiva com o monopólio católico que representava a religião nacional.

Seguindo Freston (1998) friso o caráter endógeno de apropriação do protestantismo e do pentecostalismo por determinados grupos/sociedades específicas, como as indígenas, pois a partir dele podemos não só visualizar as formas como esse processo se deu, mas principalmente como foram incorporadas e ressignificadas por sociedades e contextos distintos das de origem, com outras concepções cosmológicas e organizações socioculturais.

Em relação aos povos indígenas, algumas abordagens teóricas tenderam a ver o protestantismo e o pentecostalismo como elementos exógenos fomentadores de problemas e que particularmente (pre) tendiam amofinar a 'cultura' e a 'religião tradicional' desses povos, uma visão que me parece ainda relacionada às teorias aculturativas e a noção dicotômica entre concepções como a de 'tradicional' e 'moderno'; lembra-me o que Oliveira Filho (1998) aponta, em relação aos índios do nordeste, como "etnologia das perdas".

Isso claro sem generalizações, afinal há que se contextualizar as várias e diferentes situações vivenciadas pelos povos indígenas e suas próprias estruturas sociais e, também sem perder de vista que a inserção do cristianismo entre os povos indígenas é parte do processo 
'civilizador' empreendido pelo colonialismo aqui no Brasil e alhures. Porém, também não posso menosprezar o protagonismo de determinados povos que se apoderaram e ressignificaram tais doutrinas como sujeitos de suas próprias histórias.

Assim, penso ser interessante apontar que muitas vezes a noção de 'tradição' a que tais linhas teóricas se referem no caso dos povos indígenas na América do Sul, é uma elaboração construída a partir do contexto de contato com a sociedade nacional e, no mais, com o catolicismo e, com relação a este e ao protestantismo e pentecostalismo, não se mostra como uma construção sincrética, mas sim como uma reelaboração de conotação endógena que se pauta na visão de mundo que especifica esses povos e não efetivamente com as doutrinas em questão.

Com similaridades e diferenças marcadas histórica e culturalmente, o fenômeno protestante e pentecostal entre os povos indígenas, nos mostra sua grande plasticidade doutrinária e litúrgica, ao se inserir e ser reinterpretado por outras culturas. Creio que a ideia que considera este fenômeno como representante da sociedade ocidental e que possui um papel legitimador de diferenças em conformidade com o status-quo, se enfraquece quando nos deparamos com trabalhos como, por exemplo, o de Rappaport (1984), entre os Paez e Guambianos da Colômbia, ou o de García (1994), entre os povos dos Altos de Chiapas, México.

Entre eles, este movimento religioso foi interpretado e contextualizado como um elemento de resistência, de formulação endógena e com consequências tanto religiosas quanto políticas. Rappaport (1984) examina em seu trabalho a natureza da resistência dos 'evangelistas nativos' em diversas missões protestantes nas terras altas do sul da Colômbia. Para Rappaport (1984), estes conversos realizam uma minuciosa seleção entre os aspectos da nova ideologia que estão dispostos a aceitar ou rechaçar.

No mesmo sentido, García tece uma crítica argumentando que,

Esta idea de que los indígenas dividen a sus comunidades al adoptar una fe diferente del catolicismo, es resultado de concebir el monolitismo religioso como sinónimo de identidad natural que no debe ser perturbada por creencias extrañas a los pueblos indios (GARCIA, 1994: 6).

No México, Navarro (1984) nos descreve o sistema de cargos religiosos hierarquicamente estruturados a partir da ótica do catolicismo, que tomou ares de religião tradicional e da política dominante, servindo como um mecanismo de controle e conflito 
interno entre os Totonaca e alimentando entre eles uma diferenciação econômica e política que foi não só questionada como negada pelos protestantes e pentecostais nativos.

Estes são alguns poucos exemplos de pesquisas preocupadas em compreender melhor a apropriação do protestantismo e do pentecostalismo por povos cuja visão de mundo, seu arcabouço sócio cultural abarcou também as doutrinas cristãs, como parece ocorrer não só com os indígenas sul-americanos.

\section{PENTECOSTALISMO NO OESTE PAULISTA: A TERRA INDÍGENA VANUÍRE}

Da mesma maneira, as manifestações religiosas vivenciadas nas Terras Indígenas do oeste paulista podem indicar aspectos relevantes da atualidade das etnias que ali convivem em um contexto pluriétnico e plurirreligioso. Ali os Terena convivem com os Guarani, subgrupo Ñandeva-Apapokuva na T.I. Araribá; os Kaingang da família linguístico-cultural Jê, pertencente ao tronco Macro-Jê em Icatú e com estes e os Krenák, também classificados como Macro-Jê, em Vanuíre.

A T.I. Icatú foi fundada em 1916 para abrigar os recém 'pacificados' Kaingáng, provenientes do Acampamento dos Patos, atual município de Promissão. O Posto Indígena se localiza a 09 quilômetros do município de Braúna e a 35 quilômetros de Penápolis; a área compreende 120 alqueires demarcados.

$\mathrm{Na}$ década de vinte chegaram a essa reserva alguns Terena vindos de Mato Grosso do Sul, mais exatamente das aldeias Cachoeirinha e Lalima, as duas pertencentes ao município de Miranda; por essa época, Icatú se constituía em uma colônia penal indígena.

A T.I. Vanuíre também foi fundada em 1916 devido a uma cisão interna entre os Kaingáng de Icatú. Vanuíre possui 250 alqueires demarcados. Com a diminuição da população Kaingáng houve a chegada de outras etnias à área, como os Terena na década de 1940 vindos de Icatú e também da T.I. Araribá, pertencente ao município de Avaí (16 Km), distante 41 quilômetros de Bauru.

Em Vanuíre também se instalaram na década de 1950 os Krenák, provenientes de Minas Gerais. Após uma transferência dos membros dessa etnia para a área dos Maxacali pelo SPI devido à descoberta de uma mina de mica na área central de sua área indígena, alguns resolveram retornar a sua área original e os que permaneceram foram transferidos para Vanuíre; outros "se perderam pelo mundo" (PARAÍSO, 1992). 
Araribá, por sua vez, foi uma área originalmente destinada em 1911 aos Guarani, Nandeva-Apapokuva (SCHADEN, 1969), que habitavam a região na época em que os Kaingáng foram pacificados. Em 1919 o Araribá se encontrava quase desabitado devido à gripe espanhola que dizimou a população Guarani. No final da década de vinte e início de 1930, chegaram os Terena vindos do Mato Grosso do Sul, formando assim dois aldeamentos distintos no interior da reserva: Kopenotí dos Terena e Nimuendajú dos Guarani.

Aqui, minhas breves explanações acerca da T.I. Vanuíre e suas manifestações religiosas relacionadas ao protestantismo e especialmente ao pentecostalismo se pautam em dados bibliográficos e em especial a visitas realizadas entre os anos de 2006 e 2010 em companhia dos pesquisadores de tais áreas, Niminon Suzel Pinheiro (historiadora) e Robson Antonio Rodrigues (etnoarqueólogo).

A princípio, tratou-se de visitas informais em momentos de festas e comemorações, como as realizadas no Dia do Índio e na Festa do Peixe relacionada aos Kaingáng e seus afins Terena. De fato iniciei uma pesquisa de campo, mesmo que incipiente, entre 2009 e 2010 . Os dados de campo que apresentarei foram coletados em 2010.

Os Kaingáng, por exemplo, que mantiveram os primeiros contatos com católicos no século XVII e voltaram a entrar em contato novamente no século XIX, apontam o catolicismo como sua religião 'tradicional', como religião kaingáng (D’ANGELIS, 2004).

De forma semelhante aos koixomunetí (xamãs) terena (re)conhecidos como purungueiros (as), os (as) kuiâ, xamãs kaingáng, também foram influenciados pelo catolicismo, erigindo altares com santos e invocando seus nomes nas curas, bem como a festa do kuiâ, que também se revestiu do simbolismo católico se realizando no dia 06 de agosto, dia de São Bom Jesus, semelhante ao Oheokotí terena (o ano novo terena; o início de um novo ciclo cósmico) que se realiza na semana santa católica.

Retornando a minha inspiração para esse artigo, reporto-me à minha pesquisa a fim de melhor esclarecer o que esbocei logo acima.

O koixomunetí, xamã terena, pode ser designado em português como purungueiro, feiticeiro, padre e até pela nomenclatura mais difundida na cultura popular, pajé. Mas existe outro personagem que pude constatar a partir de várias conversas e benzimentos, possuir as prerrogativas propriamente xamânicas e que em terena pode ser designado como veokotí, curador em português, curandeiro. 
Os koixomuneti chamados de purungueiros em português incorporaram às suas práticas elementos do catolicismo popular e se auto-denominam católicos. Os curandeiros por sua vez, xamãs que designei como 'sob nova roupagem', podem ser tanto católicos como se reconhecerem como evangélicos. Caso emblemático é o de um curandeiro da aldeia Bananal em MS, utilizando em seus benzimentos a imposição das mãos sobre o paciente, como é de costume nos cultos pentecostais, e também não possui imagens em seu altar, como prega a doutrina protestante de forma geral. É importante salientar que tais identidades religiosas entre os xamãs terena e possíveis filiações doutrinárias só ocorreu com a chegada do protestantismo e sua apropriação e ressignificação pelos Terena.

Tais aspectos parecem indicar uma das possíveis releituras do sistema xamânico entre os Terena, em especial após a incorporação do protestantismo, com a figura do xamã, suas técnicas e a forma de atuar estabelecidas e reunidas atualmente sob a rubrica de curandeiro, na tentativa aparentemente de anular a ambivalência que marca o poder do xamã, sendo a esse personagem que os evangélicos, membros de igrejas evangélicas, recorrem, em especial nos casos de doença.

O pentecostalismo está presente nas 3 T.Is especialmente representado pelas igrejas Congregação Cristã no Brasil (CCB) seguida pela Assembleia de Deus (AD). Como mencionei, nesse artigo me aterei a breves observações realizadas na T.I. Vanuíre.

À época da pesquisa de campo, as igrejas da CCB haviam se instalado a aproximadamente uma década, tanto em Vanuíre sendo frequentada em grande parte pelos Krenák e Kaingáng próximos ao grupo Krenák. (Caderno de campo. 2010).

Em Vanuíre, a $\mathrm{AD}$ possuía ainda somente um pequeno salão, pois a proposta de construção de um templo dentro da T.I., trazida à aldeia por um membro Terena proveniente do Pantanal sul-mato-grossense, cuja família extensa se encontra em Vanuíre desde a década de 1950, ainda estava em discussão na Fundação Nacional do Índio (FUNAI). Mas já havia ocorrido uma ruptura dentro desta AD liderada por um Kaingáng, representante de prestígio em Vanuíre. (Caderno de campo. 2010).

Um aspecto recorrentemente enfatizado pelos membros tanto da CCB como da AD em Vanuíre é o de que, com a conversão, o novo adepto se afasta de antigos grupos de convivência, se relacionando mais com os 'irmãos' e as atividades vinculadas à igreja. O mais importante é que isso significa, particularmente no caso dos homens, o afastamento das 
bebidas alcoólicas e uma considerável mudança individual e familiar, além dessas igrejas se constituírem em uma rede de comunicação e ajuda mútua (MARIZ, 1994)

A questão das bebidas alcoólicas, um dos mecanismos de dominação mais sórdidos e duradouros disseminado pela sociedade não-indígena no oeste paulista, é fato relevante, como em várias aldeias indígenas brasileiras. Neste caso, a proximidade com os centros urbanos possibilita e facilita seu consumo causando muitas vezes desavenças, entre os próprios indígenas e entre eles e os não-indígenas, que muitas vezes terminam em óbitos.

Além da questão que devemos considerar sobre o processo de apropriação do catolicismo quanto do protestantismo ou do pentecostalismo em contextos socioculturais diferenciados, por exemplo, como entre os povos indígenas, a análise das religiões e formas de religiosidade presentes nas aldeias permite apreender outras dimensões da vida social, como as conjunturas étnico-políticas que parecem se expressar nitidamente na tônica religiosa vivenciada nas aldeias, como a ruptura do grupo Kaingáng com o grupo Terena que conviviam na $\mathrm{AD}$ de Vanuíre (pode-se conjecturar que esta cisão não se limitou ao aspecto religioso).

Apesar do caráter na maioria das vezes impositivo e violento desses 'encontros religiosos', o que desejo ressaltar são as possibilidades de criações e reelaborações socioculturais, cosmogônicas, cosmológicas, escatológicas, políticas, tema de um interessante comentário de Lawrence Sullivan:

Não há motivo nenhum para duvidar de que as religiões e escatologias sul-americanas fossem os produtos de histórias complexas e pluralistas muito antes da introdução do cristianismo. Que o encontro com o cristianismo foi acompanhado por devastação é inegável. ... Mas os sul-americanos já estavam equipados para reconhecer os sinais de mudança cultural radical e do fim do mundo simbólico. Já tinham escatologias próprias. O imaginário trágico e destrutivo, ou os retratos de uma idade dourada provindo das suas próprias tradições míticas, ajudavam-nos a enfrentar a mudança e renovação com criatividade. As maneiras como os paradigmas religiosos nativos absorveram e transformaram as escatologias cristãs são o fruto imprevisível da sua história criativa de envolvimento com o sagrado. ... (SULLIVAN apud WRIGHT, 1999: 10).

Nesse sentido, creio ser complicado trabalhar com noções como a de 'tradicional' e 'moderno', pois a identidade de evangélico, bem como a de católico que só se pôs no cenário religioso com a introdução do protestantismo e do pentecostalismo entre determinadas sociedades indígenas, fundamentando novas alteridades, não exclui ou se sobrepõe à concepção/visão de mundo que caracteriza tais povos, esta sim, se impondo em vários 
momentos como marcador de diferenças mais profundas, inclusive e especialmente diante de tais doutrinas.

\section{Á GUISA DE CONCLUSÃO}

Penso que as manifestações de religiosidade expressam criativamente novas formulações, etnogêneses, como coloca Wright (1999: 2004), que podem surgir em um quadro pluriétnico, em contato permanente com a sociedade não-indígena e com suas particularidades no que diz respeito aos elementos característicos da visão de mundo desses povos.

O contexto vivenciado no oeste paulista, por exemplo, a convivência em um mesmo território entre diferentes etnias e também com elementos da sociedade nacional, como as religiões cristãs, como as pentecostais, parece se adequar ao que Wright (1999) denomina de "campos inter-religiosos de identidade", ou seja, as maneiras pelas quais os povos indígenas moldam o cristianismo, e que permite apreender o dinamismo sociocultural e seus encadeamentos também políticos.

Desejo finalizar com uma citação de Sahlins, do artigo O Pessimismo sentimental, onde o autor expõe que, “... é assim que se faz hoje a história cultural, em um intercâmbio dialético do global com o local. Pois ficou bem claro agora que o imperialismo não está lidando com amadores nesse negócio de construção de alteridades ou de produção de identidades" (SAHLINS 1997: 133).

\section{REFERÊNCIAS BIBLIOGRÁFICAS}

ACÇOLINI, Graziele. 2004. Protestantismo à moda Terena. Tese de Doutorado em Antropologia, Universidade Estadual Paulista.

BITTENCOURT FILHO, José. 1989. "Remédio Amargo". In: ANTONIAZZI, Alberto et al. Nem anjos nem demônios: interpretações sociológicas do pentecostalismo. 2 ed., Petrópolis, Vozes, p. 24-33.

D’ANGELIS, 1994. "O SIL e a redução da língua Kaingang à escrita: um caso de missão 'por tradução"”. In: WRIGHT, Robin (org.). Transformando os deuses. Igrejas evangélicas, pentecostais e neopentecostais entre os povos indígenas no Brasil. V. II, Campinas, Ed. da UNICAMP, p. 112. 
FRESTON, Paul. 1994. "Breve história do pentecostalismo brasileiro". In: ANTONIAZZI, Alberto et al. Nem anjos nem demônios: interpretações sociológicas do pentecostalismo. Petrópolis, Vozes, p. 67-99.

FRESTON, Paul. 1998. Pentecostalism in Latin America: characteristics and controversies. Social Compass. International Review of Sociology of Religion, v. 3, n.45, p. 335-358.

GARCIA, Carlos Martinez. 1994. Las iglesias indígenas protestantes y la situacion politica en Chiapas. Ponencia presentada en la Third Interamerican Missiological Consultation: the social and religious significance of the grown of Latin America Protestantism. Philadelfia, october 6-8, p.1-26.

MARIANO, Ricardo. 1999. Pentecostais. Sociologia do novo pentecostalismo no Brasil. São Paulo, Loyola.

MARIZ, Cecília Loreto. 1994. "Libertação e ética: uma análise do discurso de pentecostais que se recuperaram do alcoolismo". In: ANTONIAZZI, Alberto. Nem anjos nem demônios: interpretações sociológicas do pentecostalismo. Petrópolis, Vozes, p. 204-224.

MENDONÇA, Antonio Gouvea e Velasques Filho. 1990. Procópio: Introdução ao protestantismo no Brasil. São Paulo, Loyola.

MENDONÇA, Antonio Gouvea. 1982. O celeste porvir: um estudo sobre a inserção do protestantismo na sociedade brasileira. Tese de doutorado em Antropologia, FFLCH/Universidade de São Paulo.

NAVARRO, Carlos Garma. 1984. Liderazgo protestante en una lucha campesina. México: América Indígena, v. 44, n. 1, enero-marzo, p. 127-141.

OLIVEIRA FILHO, João Pacheco. 1998. Uma etnologia dos “índios misturados”? Situação colonial, territorialização e fluxos culturais. MANA. Rio de Janeiro, Estudos de Antropologia Social, v. 4, n.1, p. 47-76.

PARAÍSO, Maria Hilda B. 1992. "Os Botocudos e sua trajetória histórica”. In: CUNHA, Manuela Carneiro da (org). História dos índios no Brasil. São Paulo, Cia. das Letras, FAPESP, p. 413-430.

PINHEIRO, Niminon Suzel. 1999. Vanuíre: conquista, colonização e indigenismo. Oeste paulista, 1912-1967. Tese de Doutorado em Antropologia, FCL/Universidade Estadual Paulista.

RAPPAPORT, Joanne. 1984. Las misiones protestantes y la resistencia indígena en el sur de Colombia. México. América Indígena, v. 44, n.1, enero-marzo, p. 111-141.

RODRIGUES, Robson Antonio. 2007. Os caçadores-ceramistas do sertão paulista: um estudo etnoarqueológico da ocupação Kaingang no vale do rio Feio/Aguapeí. Tese de Doutorado em Arqueologia, Universidade de São Paulo. 


\section{Nanduty}

ISSN:2317-8590

SCHADEN, Egon. 1969. Aculturação Indígena. São Paulo, Ed. da Universidade de São Paulo.

WRIGHT, Robin. 2004. Transformando os Deuses. Igrejas evangélicas, pentecostais e neopentecostais entre os povos indígenas no Brasil. São Paulo, Editora da Unicamp.

Transformando os Deuses. 1999. Os múltiplos sentidos da conversão entre os povos indígenas no Brasil. Campinas, Editora da Unicamp. 